\title{
MEMÓRIAS DAS EXPERIÊNCIAS DE EJA DA UNIVERSIDADE FEDERAL DE SÃO CARLOS E DA UNIVERSIDADE DE BRASÍLIA
}

\author{
Maria Luiza Ferreira Duques \\ Cláudio Eduardo Félix dos Santos
}

\section{Resumo}

Este estudo enfoca propostas de Educação de Jovens e Adultos-EJA implementadas em duas universidades públicas brasileiras, a partir da década de 1980 e, objetiva analisar as concepções formativas presentes nas experiências de EJA desenvolvidas na Universidade Federal de São Carlos-UFSCar e na Universidade de Brasília-UnB. O estudo estabelece uma aproximação com o método materialista histórico dialético. Os resultados apontam o desenvolvimento, por parte das propostas, de uma concepção formativa específica para a EJA. As experiências pautaram numa ação de luta e resistência no campo dos direitos, funcionando como espaços indutores de transformação das realidades sociais. As memórias dos educadores revelaram o alcance que as propostas possuem tanto para as universidades, quanto para a reconfiguração da EJA no Brasil.

Palavras-chave: memórias; EJA; UFSCar; UnB

\section{MEMORIES OF EJA EXPERIENCES FROM THE FEDERAL UNIVERSITY OF SÃO CARLOS AND THE UNIVERSITY OF BRASÍLIA}

\begin{abstract}
This study focuses on Youth and Adult Education-EJA proposals implemented in two Brazilian public universities, from the 1980s onwards, and aims to analyze the formative concepts present in the EJA experiences developed at the Federal University of São Carlos-UFSCar and the University of Brasilia-UnB. The study establishes an approximation with the dialectical historical materialist method. The results point to the development, on the part of the proposals, of a specific formative conception for EJA. The experiences were based on an action of struggle and resistance in the field of rights, functioning as spaces that induce the transformation of social realities. The educators' memories revealed the scope that the proposals have both for universities and for the reconfiguration of EJA in Brazil.
\end{abstract}

Keywords: memories; EJA; UFSCar; UnB

\section{RECUERDOS DE EXPERIENCIAS EJA DE LA UNIVERSIDAD FEDERAL DE SÃO CARLOS Y LA UNIVERSIDAD DE BRASILIA}

Resumen

Este estudio se centra en las propuestas de Educación para Jóvenes y Adultos-EJA implementadas en dos universidades públicas brasileñas, desde la década de 1980 en adelante, y tiene como objetivo analizar los conceptos formativos presentes en las experiencias EJA desarrolladas en la Universidad Federal de São Carlos-UFSCar y la Universidad de Brasilia-UnB. El estudio establece una aproximación con el método dialéctico histórico materialista. Los resultados apuntan al desarrollo, por parte de las propuestas, de una concepción formativa específica para EJA. Las experiencias se basaron en una acción de lucha y resistencia en el campo de los derechos, funcionando como espacios que inducen la transformación de las realidades sociales. Los recuerdos de los educadores revelaron el alcance que tienen las propuestas tanto para las universidades como para la reconfiguración de EJA en Brasil. 
Palabras clave: recuerdos; EJA; UFSCar; UnB

\section{INTRODUÇÃO}

Após um longo período em que a Educação de Jovens e Adultos-EJA ocupou um lugar marginal no âmbito das políticas educacionais, o movimento a favor da modalidade retoma sua relevância, inscrevendo-a nas agendas das políticas públicas nacionais e evidenciando novas formas de construir propostas voltadas aos jovens e adultos alijados dos processos de escolarização. Depreende-se, pois, que o espaço destinado à EJA no conjunto das políticas públicas, se confunde com o lugar social endereçado aos setores populares da sociedade, essencialmente, quando "[...] os jovens e adultos são trabalhadores, pobres, negros, subempregados, oprimidos, excluídos" (ARROYO, 2001, p. 10).

Enquanto modalidade da educação básica direcionada aos indivíduos que não tiveram oportunidade de estudar, no tempo tido como adequado, a EJA, assegurada pelo artigo 37 da Lei de Diretrizes e Bases da Educação, n. 9394/96 (BRASIL, 1996), deve considerar as especificidades dos alunos e suas trajetórias de vida, na maioria das vezes, marcada pelo trabalho e por exclusão social.

Diante da existência de propostas de EJA, em algumas universidades, este estudo se concentra nas experiências de EJA desenvolvidas por duas universidades públicas brasileiras. Com base no histórico, no impacto na área e na relevância para os envolvidos, foram eleitas as propostas de EJA que tiveram início na década de 1980 na UFSCar e na UnB.

A experiência de EJA desenvolvida pela UFSCar foi implantada no início de 1980, visando a alfabetização dos funcionários carentes de escolarização, que atuavam na universidade. Instituído no período que marcou a eleição para reitor da UFSCar, o Programa de Alfabetização de Funcionários-PAF nasceu da constatação da existência de trabalhadores analfabetos na universidade e acabou funcionando como um espaço em que se garantia a escolarização e a formação crítica dos servidores, ao passo que, promovia a formação docente dos graduandos das licenciaturas da UFSCar que atuavam como alfabetizadores.

O Projeto de Alfabetização e Formação de Alfabetizadores de Jovens e Adultos de Camadas Populares-Projeto Paranoá da UnB, desenvolvido na cidade satélite de Paranoá no Distrito Federal, surge em 1985, tendo sua origem articulada ao processo histórico da construção de Brasília, já que a cidade do Paranoá surgiu através de acampamentos de obras construídos com a finalidade, naquele período, de alojar os trabalhadores que atuavam na construção da barragem formadora do Lago Paranoá. Após findar a construção, inúmeras famílias permaneceram no local e mediante constantes invasões e resistências, por parte dos alojados, consolidou-se o maior assentamento urbano do Distrito Federal.

Diversos embates se estabeleceram com o governo, que mediante repressão, tentou convencer os moradores a deixarem o Paranoá e, foi nesse movimento, que a EJA se apresentou como necessária ao fortalecimento da luta. A comunidade do Paranoá buscou apoio na UnB para o processo de alfabetização dos moradores e, consequentemente, para o aprimoramento das discussões em prol da conquista da moradia. Foi focalizado na alfabetização dos moradores do Paranoá que nasceu o Projeto de EJA da UnB.

Enfocar os episódios envolvendo as universidades durante o início da década de 1980, período em que a ditadura militar ainda mostrava supremacia, é uma maneira de evidenciar um universo de muitas lutas, mas que também logrou conquistas para o país. Muito embora o regime militar tenha se mantido pelo poder autoritário de suas lideranças, acabou desenvolvendo 
importantes políticas, muitas vezes contraditórias (MOTTA, 2014), mas cujo legado segue prestando contribuições. No âmbito da universidade, reformas, financiamentos em pesquisas e cursos de pós-graduação marcaram um contraditório período que permanece vivo, seja pela via da historiografia, seja através das memórias de quem vivenciou tão intenso momento.

Foi nesse período, marcado por tensões, que em algumas universidades públicas brasileiras, iniciativas de EJA floresceram, demonstrando que o projeto de governo que perdurou nas décadas de 1970 e 1980, ao mesmo tempo em que devastou, conseguiu ser reformador. Ao mesmo tempo em que impôs, abriu espaços para o surgimento de grupos contra hegemônicos, a exemplo dos educadores que inseriram a EJA nas pautas das universidades. Nesse sentido, nosso estudo objetivou analisar, mediante as memórias de educadores, as concepções formativas presentes nas experiências de EJA desenvolvidas na UFSCar e na UnB.

Consideramos interessante enfocar as experiências de educadores, cujas trajetórias se imbricam com os movimentos de transformação social. Para isso, é preciso considerar a memória e a experiência desses educadores, no sentido de retomar a atuação e militância junto aos jovens e adultos de camadas populares. A memória, quando cotejada com a história, ajuda a retomar a riqueza de experiências de uma determinada conjuntura. "Reconhece-se, assim, o lugar que sociedades, ideologias, culturas e lutas políticas marcam a memória". (JELIN, 2012, p. 25).

Através das memórias, podemos entender a história das lutas sociais que implicam nos processos educativos desenvolvidos com a população de jovens e adultos.

\section{CAMINHOS METODOLÓGICOS}

O desenvolvimento do estudo tem nos direcionado a uma aproximação com o método materialista histórico, nos oportunizando a constatação de que, tal como anunciado por Marx (1980), todo o começo é difícil em qualquer ciência. Diante das dificuldades em iniciar os estudos e buscar a compreensão de processos históricos, firmados em períodos cujo acesso a informações se fez desafiador pela própria característica do momento, ainda marcado por certo controle e vigilância, fomos impelidos a buscar mecanismos que nos permitissem escavar as informações relevantes ao estudo, mantendo os cuidados éticos inerentes à investigação científica. As análises empíricas se estruturaram através de entrevistas e estudos de documentos, de modo a explorar os referenciais teórico-metodológicos em consonância com o retorno das memórias dos educadores.

$\mathrm{Na}$ tentativa de buscar as memórias de grupos de educadores que dialogaram na construção de experiências de EJA, em contextos sociais nem sempre favoráveis, adotamos para este estudo, a memória entendida como elemento social, formulada mediante a interação entre sujeitos sociais. Para compreensão das experiências de EJA, realizamos um esforço de aproximação com a memória social $^{1}$, desenvolvida por Halbwachs desde 1925, em seus "Quadros Sociais da Memória” (2004), também formulada em sua "Memória Coletiva" (2003), quando afirma que no âmbito da memória, o individual se desenha no coletivo, compreendendo a memória como a reelaboração de vivências ou experiências reconhecidas pelos grupos.

Considerando, assim como Halbwachs (2003, p. 69), que "[...] são os indivíduos que se lembram, enquanto integrantes do grupo", desenvolvemos um processo de escuta das reminiscências dos nossos informantes, de modo individual, a fim de articular os elementos coletivos de composição da memória viva das experiências que pesquisamos.

\footnotetext{
1 Memória Social é um conceito atribuído aos estudos de Halbwachs (2003; 2004), que considera a memória como uma reconstrução do passado, a partir dos marcos sociais do presente. O conceito de memória social agrega o direito à memória e a contra memória de grupos socialmente marginalizados e oprimidos pela "memória nacional".
} 
Para entender o contexto do período de surgimento das experiências de EJA, contemplamos a memória numa perspectiva materialista histórica dialética, que acolhe a premissa de que os indivíduos e os grupos sociais produzem suas memórias como produto do mundo material em que historicamente estão situados.

Ao pensar a produção do conhecimento científico numa concepção materialista histórica, especialmente nas ciências humanas, é preciso buscar captar a lógica própria do objeto. Através desse método é possível compreender e analisar a história, as lutas e as evoluções econômicas e políticas, achados que este estudo possui potencial de viabilização. Como observou Marx (1980), a pesquisa tem que captar detalhadamente a matéria, analisar suas várias formas de evolução e rastrear sua conexão íntima. Só depois de concluído esse trabalho é que se pode expor o movimento real.

Entendemos, assim como Ricoeur (2007), que mesmo sendo a memória alvo de desconfianças, ela ainda constitui nosso último referencial a procura do que se passou. As experiências da UFSCar e da UnB, retomadas mediante as memórias dos educadores, apresentaram significativo destaque no período de reabertura política e mesmo no momento atual, como é o caso da proposta da UnB que continua efetiva e prestando sua contribuição para jovens e adultos, até então, alijados do direito à educação.

\section{A EJA E A UNIVERSIDADE: ALGUMAS APROXIMAÇÕES}

As atividades voltadas a jovens e adultos analfabetos se mantiveram, por muito tempo, longe das prioridades das iniciativas políticas, sendo progressivamente abandonadas pela União (BEISIEGEL, 1997). Isso levou o movimento em prol da EJA a resgatar sua relevância, inserindoa nas agendas das políticas públicas. Esse momento tem se traduzido em avanços que apontam pistas de uma nova maneira de fazer EJA.

Avançar numa nova concepção de EJA significa reconhecer o direito a uma escolarização para todas as pessoas, independentemente de sua idade. Significa reconhecer que não se pode privar parte da população dos conteúdos e bens simbólicos acumulados historicamente e que são transmitidos pelos processos escolares. Significa reconhecer que a garantia do direito humano à educação passa pela elevação da escolaridade média de toda a população e pela eliminação do analfabetismo (HADDAD, 2007, p. 15).

Não é difícil perceber, diante do entendimento que se vem alcançando sobre a EJA, que essa modalidade de educação tem suas especificidades e que a depender do momento histórico em que iniciativas de EJA são gestadas, as marcas de atuação podem se apresentar de maneiras bastante distintas. $\mathrm{O}$ fato deste estudo se concentrar em iniciativas que emanaram de duas universidades públicas, através da ação de educadores comprometidos com a educação de adultos de classes populares, denota nosso desejo sobre determinadas formas de fazer a EJA, em estreita preocupação com as especificidades dos sujeitos trabalhadores.

O desenvolvimento de propostas que reconheçam as especificidades dos sujeitos da EJA perpassa por aspectos como a elaboração de currículos que acolham as peculiaridades dos educandos trabalhadores, incluindo a flexibilidade dos tempos e espaços, a construção de instrumentais didáticos que desenvolvam as potencialidades desses sujeitos e, sobretudo, o empenho, por parte dos educadores, pela transformação das realidades dos educandos. Esses foram alguns apontamentos que nos fizeram investigar as propostas de EJA das universidades em questão. 
As conexões entre a EJA e a universidade se constroem sobre uma perspectiva, no mínimo, complexa. De um lado, temos uma modalidade forjada no interior das classes populares e destinada ao atendimento de minorias sociais, cujos saberes são constituídos, em quase sua totalidade, pela experiência; do outro, encontra-se uma instituição voltada à produção de conhecimentos científicos e saberes eruditos, de onde surgem relações de saber e poder bastante desiguais.

Os projetos de EJA desenvolvidos em universidades, geralmente, carregam em sua tradição a via da extensão universitária. É por esse viés que se apresenta a história das primeiras iniciativas acerca da integração entre a EJA e a universidade (IRELAND, 2001). A complexidade dessa relação é tão clara que, historicamente, a via de ingresso mais premente da EJA na universidade ocorre pela extensão e, exatamente a extensão figura o componente menos privilegiado da tríade: ensino, pesquisa e extensão. A EJA acaba recebendo, portanto, pela via da academia, um espaço de prestígio inferior.

Estudos desenvolvidos com ênfase nos anos 1970 e 1980 apontam a existência de tensões muito evidentes na relação entre EJA e universidade. Haddad (1989), desenvolveu uma pesquisa sobre a atuação de instituições de ensino superior no Brasil, focalizando programas de escolarização para jovens e adultos. Nessa investigação, o autor constatou que mesmo as ações desenvolvidas pelas universidades tendo um objetivo similar, as concepções adotadas por cada instituição acabam sendo bem distintas. As ações voltadas à intervenção, geralmente eram motivadas por demandas dos próprios funcionários das instituições. Com isso, os programas de escolarização de funcionários, por muito tempo, se apresentaram como a principal forma de atuação das universidades frente à EJA.

Como muitos programas de EJA eram pensados para atacar a deficiência na formação de servidores, muitas propostas seguiam a via da prestação de serviço e, consequentemente, a articulação desses programas com a pesquisa e o ensino acabava sendo bastante incipiente. Essa ínfima articulação de propostas de EJA com o corpo da universidade tem uma tradição histórica percebida e enfatizada, inclusive, por professores universitários engajados na luta a favor da EJA. O próprio Haddad (1989), constatou que as iniciativas de EJA, em quase sua totalidade, eram ações que partiam de uma pessoa ou grupo restrito de interessados na área, implicando em maiores esforços para desenvolver os projetos.

Como muitos programas de EJA existentes em universidades brasileiras surgiram, basicamente, por exigências de formação de servidores ou mesmo para atendimento de algum preceito legal, a construção dessas propostas nem sempre acontecia com a estreita participação dos educandos. Com isso, os programas de EJA, salvo raras exceções, já nasciam póstumos.

Mesmo sendo a relação entre EJA e universidade, ainda permeada por indefinições, não se pode desconsiderar a contribuição da universidade para o fortalecimento da modalidade. As propostas de EJA implementadas nas universidades evidenciam essa colaboração.

Com o intuito de conectar experiências da comunidade com a produção da academia, alguns movimentos populares ressurgiram no final dos anos 1970 e início dos anos 1980, enfatizando a relação entre EJA e universidades. Como modo de organizar as propostas para além dos muros das universidades, em 1987, foi criado o atual Fórum de Pró-Reitores de Extensão das Instituições de Educação Superior Públicas Brasileiras-FORPROEX. Nas discussões do Fórum, os programas com fins ao atendimento das demandas da comunidade deveriam ser tomados como processos educativos, culturais e científicos capazes de promover a articulação entre o ensino e a pesquisa, já que essas seriam as vias de reencontro entre o saber acadêmico e o saber popular.

No caso das experiências aqui analisadas, cujas atuações se mostraram comprometidas com as necessidades dos sujeitos trabalhadores, a investigação das concepções de formação humana se 
mostrou importante para o entendimento da constituição de cada proposta e suas consequentes possibilidades de transformação das realidades sociais dos envolvidos.

\section{AMPLIANDO OLHARES SOBRE AS PROPOSTAS DE EJA}

A elaboração de propostas de trabalho que tenham como cerne a formação de sujeitos isentos de escolarização, reconhecendo, portanto, as especificidades desses sujeitos, perpassa por diversos aspectos, dentre os quais o reconhecimento desses sujeitos como trabalhadores. Foi partindo da realidade objetiva dos sujeitos expropriados dos seus direitos, e aqui se inclui o direito à educação, que professores de algumas universidades lutaram por programas de EJA em suas instituições de atuação. Dentre esses programas, enfocamos o PAF da UFSCar e o Projeto Paranoá da UnB.

O Programa da UFSCar surgiu em um período em que as experiências no âmbito da EJA estavam ganhando corpo na sociedade civil e sendo discutidas em instituições como as universidades, mas naquele período, o envolvimento das universidades com a EJA, em suas poucas ocorrências, ainda se dava pela extensão. A EJA ainda não era reconhecida como direito e o seu oferecimento ocorria sem que a modalidade fosse tomada como uma política pública.

O PAF foi gestado em 1980, visando o atendimento das solicitações dos funcionários que atuavam na UFSCar e que, por motivos vários, não tiveram oportunidade de escolarização. $\mathrm{O}$ grupo de alfabetização foi criado na UFSCar em decorrência da motivação imediata da eleição para reitor, quando se descobriu a existência de um número considerável de servidores não alfabetizados. Diante dessa constatação, educadores com engajamento político e pedagógico no âmbito das lutas por EJA se mobilizaram na formulação do Programa.

A implementação do PAF ocorreu no momento em que a proposta de alfabetização de adultos de bases freireanas trazia discussões sobre a importância da dimensão política da educação e sobre o real papel da escola na socialização do conhecimento historicamente produzido. Desse modo, o Programa se constituiu num espaço privilegiado de amadurecimento dessas ideias, ao promover a experimentação de um processo de alfabetização em que a participação efetiva dos alfabetizandos propulsionava a aprendizagem desses, ao passo que o trabalho pedagógico desenvolvido, assegurava a formação dos educadores. O PAF desempenhava, pois, uma dupla função em que, à proporção que os coordenadores focavam na escolarização dos educandos, cumpria-se, também, o objetivo da formação dos educadores, estudantes das licenciaturas que exerciam docência no Programa.

A proposta não buscava apenas a garantia dos rudimentos do "ler e escrever", o PAF continha, também, um caráter de formação de consciência crítica e política. Atrelado a esses intentos, estava o objetivo da realização de pesquisas e estudos no âmbito da EJA. Dessa forma, desde o começo dos trabalhos, a coordenadora Betty Oliveira se empenhou junto aos pesquisadores e graduandos dos cursos de licenciatura da UFSCar, no sentido de garantir a produção científica e a divulgação sistematizada do Programa.

Desenvolvendo um trabalho numa perspectiva de valorização dos saberes dos educandos, o PAF se construiu num movimento de valorização das experiências e dos conhecimentos dos educandos. Ao logo de sua vigência (1980-1985), foram realizadas atividades como o Seminário de Aperfeiçoamento dos Trabalhadores, promovido em 1981, oficinas com o protagonismo dos educandos, debates, encontros, além da produção do material didático como os Livros de Leitura 1 e 2, ancorados nos textos dos alfabetizandos e, posteriormente, revisados e organizados pela coordenação, mediante orientação daqueles que prestavam assessoria ao PAF, a exemplo de Paulo 
Freire, Elza Freire, Dermeval Saviani, dentre outros educadores que contribuíram com a experiência da UFSCar.

Mediante a experiência do PAF, foi instituído o Programa de Educação de Adultos-PEA, que se constituiu na organização integrada de todas as atividades de EJA desenvolvidas na UFSCar. Foi também através do PAF que se consolidou um trabalho inovador na área da matemática, cuja propulsão se deu com o empenho do professor Newton Duarte que conseguiu unir teoria e prática na confecção e exploração de ábacos em tamanhos ampliados. Pela perspectiva crítica assumida pelo Programa, houve a produção coletiva do Jornal Participando, produto da participação efetiva dos educandos que traziam as situações de suas vivências para as discussões, vindo após os debates, a compor os textos do Jornal.

A iniciativa foi considerada uma das experiências de alfabetização de adultos mais bem refletida e avaliada (FÁVERO; SIQUEIRA, 2016), em que além do material didático, foi capaz de provocar discussões e contribuir para a produção de documentos e estudos que ajudam a compor a memória da EJA, além de ter sido um laboratório para construção de formas de ensinar e de aprender em uma época em que tornar a educação um ato político não só era difícil, como perigoso.

O Projeto da UnB, convencionalmente chamado de Projeto Paranoá, tem sua formação imbricada à história de constituição de Brasília e suas interfaces com o êxodo rural. Em busca de melhores condições de vida, muitos migrantes abandonaram suas terras para arriscarem a vida na recém-construída capital brasileira. Movidos pela necessidade de garantir uma moradia, os assentados se organizaram em prol da necessidade de sobrevivência. Nos enfrentamentos por ocupação da terra, vários embates se estabeleceram com o executivo do Distrito Federal que, através da repressão, tentou convencer os assentados a deixarem o Paranoá e se instalarem em outros espaços.

As contradições provenientes do aparato do Estado, que negava às populações do Paranoá o direito à sobrevivência, culminaram num movimento de mobilização iniciado pelos jovens do Paranoá e abraçado pelos demais moradores, na perspectiva de lutar pela regularização da ocupação das terras e pelos bens e serviços inerentes à sobrevivência das famílias. Segundo Reis (2011), essa mobilização brotou da ação de um grupo de jovens católicos que, avançando na reflexão religiosa, fundaram um movimento comunitário, entendido como o primeiro grupo com cunho político do Paranoá, o Grupo Pró-Moradia.

Com a organização dos grupos do Paranoá em associações de moradores e movimentos reivindicatórios por direitos, o governo reorganizou sua tática e tentou enfraquecer o movimento. Foi diante da ameaça do governo à comunidade do Paranoá que os moradores buscaram aliados "externos", com engajamento nas pautas populares. Nesse caso, foram alguns professores da UnB que se juntaram aos moradores do Paranoá, compondo uma espécie de intelectuais orgânicos das classes populares a favor das causas coletivas dos moradores. E para enfrentar as forças do governo, a luta pela alfabetização de jovens e adultos foi entendida como primordial.

A EJA se colocava, portanto, como necessária ao fortalecimento da luta coletiva dos moradores do Paranoá, e foi através do compromisso firmado pela UnB, através de educadores sensíveis à condição dos que não liam e nem escreviam, que "[...] o projeto surge com o objetivo não somente de alfabetizar, mas de transformar os moradores em sujeitos críticos e conscientes dos seus direitos" (SOARES, 2011, p. 311).

De acordo os relatos dos educadores comprometidos com a alfabetização dos moradores do local, o processo ensino-aprendizagem desenvolvido pela UnB e por educadores do Paranoá, visava, essencialmente, o desenvolvimento da autonomia política e a capacidade de mobilização dos moradores. Os educandos do Paranoá, por pertencerem a uma classe expropriada dos bens e serviços que ajudaram a produzir, demandavam processos de escolarização que, como dito por 
Marx (1999a), não se limitassem a interpretar o mundo, mas que cumprissem o mais importante que é transformá-lo.

Com um funcionamento que compreendia a formação de educadores por parte dos docentes da UnB e a consequente alfabetização dos educandos, os processos formativos se consolidam mediatizados pela realidade dos educandos, com as contradições do contexto econômico, político e social em que atuam.

Os depoimentos dos educadores dão conta de evidenciar que a dinâmica de funcionamento do Projeto Paranoá mantem coerência com a natureza da formação perseguida pelos mentores do projeto. As atividades desenvolvidas envolvem "Encontro de Convivência e Aprendizagem Coletiva", designado como Fórum - espaço em que ocorrem aulas coletivas com a participação dos envolvidos com o Projeto. Além de alfabetizadores e alfabetizandos, o fórum recebe dirigentes da comunidade e, por seu caráter coletivo, ajuda a identificar as situações-problemas-desafios, provocando discussões e seleções de prioridades locais.

Após serem discutidas e votadas no fórum, as situações-problemas-desafios passam a ser o eixo dorsal de referência da alfabetização, sendo diluídas nas aulas com ocorrência semanal. Como o Projeto Paranoá não trabalha com cartilhas, o material de orientação se constrói pelos envolvidos mediante os problemas enfrentados pela comunidade, embasados por pressupostos freirenos e marxistas (REIS, 2011). As metodologias de ação e as discussões e encaminhamentos com fins à superação dos problemas, em estreita sintonia com a organização popular do Paranoá, constituem os caminhos metodológicos encontrados para a construção dos modos de ensinar e aprender no Projeto.

O Projeto Paranoá apresenta uma sensibilidade política de mobilização em prol das pautas coletivas. Foi através dessa estruturação que os líderes das organizações populares conseguiram legalmente a fixação do Paranoá, e pelos enfrentamentos travados, os professores da UnB e alfabetizadores do Paranoá conseguiram alfabetizar - e continuam alfabetizando - um grande número de sujeitos, de modo a não só fazê-los ler e escrever, mas incitando a consciência crítica e a transformação das suas realidades sociais.

As duas experiências (PAF e Projeto Paranoá) nasceram em um período cujo contexto foi de resistência, de lutas e de conquistas que marcaram o movimento da sociedade a favor da redemocratização, tendo como auge a Constituição de 1988.

Diante das lutas por direitos, os educadores que perseguiram o direito à educação para as classes trabalhadoras, buscaram meios que, mesmo contrariando estruturas, foram capazes de considerar a enorme desigualdade entre as classes sociais, preservando as especificidades das condições de existência dos jovens e adultos e garantindo a eles o direito à formação. Segundo Giovanetti (2005), a EJA é caracterizada pela presença de jovens e adultos de origem popular, marcados por processos de exclusão social, marginalização cultural e exploração econômica. Os jovens e adultos que frequentam a EJA são, em sua maioria, sujeitos expropriados pelo capital e que não possuem condição de usufruto da riqueza que ajudam a produzir. São sujeitos de direitos que não gozam de direitos.

Os alunos da EJA, ao vivenciarem, pelo viés da exclusão social, o agravamento das formas de segregação - cultural, espacial, étnica, bem como, das desigualdades econômicas -, experimentam, a cada dia, o abalo de seu sentimento de pertencimento social, o bloqueio de perspectivas de futuro social (FREIRE, 2000, p. 254).

As propostas estudadas têm como referência a educação voltada aos educandos das classes populares, sendo focadas no resgate da humanidade roubada (FREIRE, 2000) e na busca pela 
formação de sujeitos críticos, políticos e epistemológicos capazes de, não somente entender suas realidades, mas para além disso, transformá-las.

\section{ANÁLISES DAS PROPOSTAS ESTUDADAS}

Ao analisar as concepções formativas das propostas de EJA da UFSCar e da UnB, alguns aspectos se mostraram evidentes, tanto no ponto em que as duas propostas se encontram, quanto em relação ao que elas se afastam.

Como já dito, as experiências aqui estudadas são produtos de um mesmo período histórico, marcado pela luta da sociedade em prol da redemocratização. Esse evento já é revelador de que muitas concepções dos educadores que se preocupavam com a pauta da EJA possuíam ressonância nos mesmos princípios.

A preocupação com o desenvolvimento de condições que conferissem aos educandos a capacidade de transformação de suas realidades desdobrou-se, em ambas as propostas, em especial atenção aos recursos didáticos para atendimento das potencialidades dos educandos. Os materiais utilizados para a alfabetização foram/são produzidos coletivamente com os educandos, externando, pois, as situações concretas das realidades daqueles sujeitos.

No exercício da construção dos materiais didáticos, na organização pedagógica e na preparação crítica, política e reflexiva dos educandos, consolidavam-se as questões centrais das propostas. As experiências da UFSCar e da UnB enfocaram a escolarização de jovens e adultos; a formação de educadores licenciandos dos cursos ofertados nas universidades analisadas e, o incentivo à pesquisa no âmbito da EJA. Essas constatações foram reforçadas por Sérgio Haddad², em entrevista realizada em maio de 2019, ao afirmar que "[...] naquela época, eram poucas as pesquisas na EJA e, portanto, essas experiências foram laboratórios de trabalho, de envolvimento de professores e alunos em sistematizar as experiências e fazer o trabalho de formação". A coerência entre esses aspectos fez/faz as perspectivas formativas das propostas, conservando em cada uma delas, suas especificidades e suas matrizes de constituição.

O estudo aponta que o PAF/UFSCar surgiu numa perspectiva de educação voltada às bases freireanas, vindo no decorrer do seu desenvolvimento, a agregar os pressupostos da pedagogia histórico-crítica em que, junto com a escolarização, promoveu a elevação da consciência crítica dos educandos. Um dos pressupostos formativos do Programa da UFSCar era a consideração do conhecimento da realidade do aluno como elemento para o processo educativo. Essa constatação foi reforçada pelas memórias do educador do PAF da UFSCar, Francisco Mazzeu, que em entrevista concedida em março de 2020, relatou:

A orientação teórica que a gente estava seguindo era adaptar o método do Freire à nossa realidade, às nossas condições. Mas o Saviani começou a fazer algumas considerações e, a partir daí, houve um esforço no sentido da aproximação com a Pedagogia Histórico Crítica. Então, a formação era muito centrada nos fundamentos teóricos filosóficos mais gerais de uma concepção pedagógica voltada à transformação da sociedade.

Das análises empreendidas acerca da experiência de EJA desenvolvida pela UFSCar, um ponto bastante evidente foi a assunção da dimensão política (OLIVEIRA, 1983) entranhada na ação pedagógica e o consequente comprometimento da ação pedagógica na transformação da

\footnotetext{
2 Sérgio Haddad desenvolveu pesquisas sobre Programas de EJA em instituições de ensino superior, entre os quais, o $\mathrm{PAF} / \mathrm{UFSC}$ ar, por isso, estabelecemos, com ele, conversas que nos ajudaram a compor a memória das propostas.
} 
sociedade. Nas palavras de Oliveira (1985, p. 52), “[...] o modo de produção da sociedade, produz/determina o modo de pensar e agir de qualquer indivíduo. No entanto, essa determinação não é absoluta". Posto dessa maneira é possível, mediante ação de educadores comprometidos com as classes populares, desenvolver uma atuação que seja capaz de contribuir com a modificação dessa sociedade. Eis, nessa interpretação, a atualidade da experiência da UFSCar que, mesmo estando fincada em um momento histórico (1980-1985), continua apresentando relevância, considerando que as análises dos produtos emanados das experiências envolvendo a EJA contribuem para o entendimento das atuais estruturas, desencadeando necessárias lutas, muitas vezes, já "apagadas" da memória.

Assim como a experiência do PAF/UFSCar, os pressupostos formativos do atual Paranoá/UnB denotam haver a consideração dos saberes trazidos pelos educandos como elementos para o processo educativo. Partindo desses saberes, evolui-se com a sistematização ancorada em princípios freireanos e marxistas, tal como revelam as memórias de Sérgio Haddad, em depoimento concedido em maio de 2019.

$\mathrm{Na}$ minha sensação, essas experiências eram freireanas, tinham a ver com essa relação entre política e educação, mas basicamente eram protagonistas da ideia da universidade entrar no campo da EJA. Pelo que me lembro, pelo que estudei da experiência da UnB, essa perspectiva freireana do trabalho junto aos moradores das cidades satélites era muito forte.

A valorização dos saberes da experiência dos educandos é um aspecto presente na proposta da UnB. Com isso, as relações entre os saberes sistematizados e a experiência social dos educandos constroem as concepções formativas do Projeto, através do que a realidade concreta aponta como problemas a serem atacados. No enfrentamento dos problemas-desafios, surgem não somente as saídas para as problemáticas vivenciadas pela comunidade do Paranoá, como também, pesquisas científicas que partem das experiências empíricas do Paranoá e se consolidam, pois, como um espaço de formação e produção de conhecimentos voltados à EJA.

O educador e pesquisador da EJA, Renato Hilário Reis, que atuou por mais de três décadas no Projeto Paranoá, esclareceu essa questão quando, em entrevista realizada em novembro de 2019, afirmou:

A situação-problema-desafio vivenciada dentro do Paranoá é que vai orientar o processo político, epistemológico, pedagógico, afetivo, amoroso daquele semestre ou ano. Discute-se, então, na sala de aula, quais são os encaminhamentos de superação e, com a coordenação do movimento popular, tem-se então, a exercitação do encaminhamento. Aí tem um sentido de contribuição transformadora.

Ao captarem a realidade vivida buscando, a partir dela, elementos para sua transformação, os sujeitos do Paranoá agem na transformação de suas realidades. A constatação de que as propostas estudadas priorizavam e, no caso da UnB prioriza, além da escolarização, o desenvolvimento de uma consciência política capaz de transformar as estruturas da sociedade, situa as experiências em uma perspectiva de formação calcada na valorização humana e no desenvolvimento de uma consciência crítica e política por parte dos educandos.

Mantendo as particularidades de cada proposta, percebemos, em ambas, aspectos que entendemos ser influências do pensamento freireano, como foi o caso das relações horizontalizadas de diálogos entre educador e educando, tomando como ponto de partida e de chegada, para o trabalho pedagógico, o respeito pelos conhecimentos dos sujeitos e, essencialmente no projeto da 
UnB, constatamos, também como orientação teórica da proposta, as inclinações marxistas, talvez pela própria influência dos coordenadores do projeto.

Dentre os aspectos constatados nas duas propostas, a perspectiva de formação capaz de incutir nos educandos jovens e adultos a criticidade necessária à luta por direitos, apresentou-se como um ponto recorrente, tal como relato proferido em novembro de 2019 por Renato Hilário Reis ao afirmar que, “[...] o Projeto Paranoá desenvolve não só a questão da leitura, da escrita, do cálculo, mas também a consciência crítica do educando e da educanda no desenvolvimento da luta por uma vida melhor".

Avançando no entendimento desse direito, os pressupostos formativos adotados com os educandos, acabam por apontar horizontes para políticas públicas no campo da EJA. Como argumenta Fávero (2009, p. 91):

Não apenas uma segunda oportunidade de escolarização, em termos do que se critica como uma "educação pobre para os pobres", mas outras formas de educação que venham a instrumentalizar indivíduos e grupos para, dizendo novamente: entender e criticar a realidade em que vivem e, em consequência, propor alternativas para sua transformação. Não mais meras e repetitivas campanhas de alfabetização, nem ofertas facilitadas do ensino copiado do sistema regular, mas ações educativas que preparem para a vida, para uma nova vida, ao longo de toda a vida.

$\mathrm{O}$ anseio perseguido pelos educadores para que os educandos conseguissem entender e criticar a realidade em que viviam/vivem e, consequentemente, buscar alternativas para transformála, aparece como aspectos latentes. As memórias dos educadores trouxeram em relevo a importância das propostas de EJA efetivadas nas duas universidades estudadas, tanto no sentido de uma formação focalizada nas necessidades da sociedade do período de surgimento das propostas, quanto na necessidade de contribuição para o contexto atual. Nesse sentido, o posicionamento de Francisco Mazzeu, revelado em entrevista conferida em fevereiro de 2020, evidencia as contribuições das propostas de EJA.

Os projetos deixaram legados. Do ponto de vista de formação de pessoas, muitas passaram pelo programa e viraram professores universitários e com produção acadêmica voltada, também, à EJA, com produção crítica no cenário educacional, de uma concepção voltada à classe trabalhadora. Então isso marcou e marca até hoje, a atuação desses profissionais que foram formados a partir da experiência de EJA da UFSCar e de outras universidades.

Mediante as lembranças de aspectos passados, a memória passa a constituir uma projeção para o que deverá nortear o porvir (RICOEUR, 2007). Os alfabetizandos participantes dos Programas de EJA da UFSCar e UnB, em função das limitações impostas, sobretudo, pelo mundo do trabalho, foram vítimas de sistemas que lhes expurgaram das oportunidades de acesso à escolarização formal, daí a preocupação dos educadores com uma formação política capaz de desencadear a consciência crítica dos sujeitos frente à transformação da realidade.

\section{CONSIDERAÇÕES FINAIS}

As concepções de formação presentes nos Programas de EJA da UFSCar e da UnB se apresentam como calcadas nos pressupostos horizontais de diálogo e participação. Com isso, as ações se mostraram sensíveis às especificidades dos educandos, de modo a reconhecê-los como sujeitos históricos e sociais alijados das oportunidades de escolarização. 
Ao revelar que os processos formativos desenvolvidos pelas iniciativas consideram as referências legitimadoras da vida adulta, como educação, trabalho e cultura, o estudo também evidencia que os educadores eram dotados de um entendimento da EJA para além da teoria e que, por militarem junto à modalidade por melhores condições de vida e formação para os educandos, foram capazes de implantar propostas que nasceram pela necessidade de alfabetização dos jovens e adultos e se ampliaram para uma ação preocupada com as classes.

O reconhecimento dos educandos da EJA como sujeitos de direito à educação e à humanidade, muitas vezes perdida, perpassa pelo entendimento desses sujeitos como construtores de cultura e portadores de experiências de vida. Como afirma Arroyo (2005), nos programas de formação, uma das questões que deve ser nuclear é a constante indagação acerca de quem são esses jovens e esses adultos com quem se vai trabalhar. Essa especificidade da situação social, étnica, cultural e econômica dos educandos, pelo que os dados puderam revelar, foi perseguida nas concepções formativas tanto do PAF, quanto do Projeto Paranoá e, é essa especificidade que precisa ser referência para a atual construção da EJA.

\section{REFERÊNCIAS}

ARROYO, Miguel. A EJA em tempo de exclusão. Revista Alfabetização e Cidadania-Rede de Apoio à Ação Alfabetizadora no Brasil, n. 11, abr. 2001.

ARROYO, Miguel. Educação de Jovens e Adultos - um campo de direitos e de responsabilidade pública. In: SOARES, Leôncio et al. (orgs.) Diálogos na educação de jovens e adultos. Belo Horizonte: Autêntica, 2005.

BEISIEGEL, Celso de Rui. A política de educação de jovens e adultos analfabetos no Brasil. In: OLIVEIRA, Dalila Andrade (org.). Gestão democrática da educação. Petrópolis, Rio de Janeiro: Vozes. 1997. p. 239-241.

BRASIL. Lei n. 9.394, de 20 de dezembro de 1996. Estabelece as diretrizes e bases da educação nacional. Brasília, 20 dez. 1996.

FAVERO, Osmar. Educação de jovens e adultos: passado de histórias, presente de promessas. In: Educação de Jovens e Adultos na América Latina. São Paulo: Moderna, 2009.

FAVERO, Osmar; SIQUEIRA, Elisa Motta de Souza. Educação Popular e Educação de Jovens e Adultos. Memória e História. In: RIBEIRO, Ana de Almeida (org.). Estudos e práticas em EJA: ampliando olhares. Rio de Janeiro: Caetés, 2016.

FREIRE, Paulo. Pedagogia da indignação. Ed. Unesp, 2000.

GIOVANETTI, Maria Amélia. A formação de educadores de EJA. Diálogos na EJA. Belo Horizonte: Autêntica, 2005.

HADDAD, Sérgio. Promoção de programas de Alfabetização, Pós Alfabetização e Educação de Adultos com a Vinculação das Instituições de Ensino Superior no Brasil. São Paulo: Centro de Documentação e Informação (CEDI), 1989.

HADDAD, Sérgio. Por uma nova cultura de Educação de Jovens e Adultos, um balanço de experiências de poder local. Novos caminhos em Educação de Jovens e Adultos - EJA. São Paulo: Global, 2007.

HALBWACHS, Maurice. A memória coletiva. São Paulo: Centauro, 2003.

HALBWACHS, Maurice. Los marcos sociales de la memoria. Barcelona, Anthropos, 2004. 
IRELAND, Timothy D. Educação de Jovens e Adultos e Extensão Universitária: Primos pobres? $13^{\circ}$ Congresso de Leitura do Brasil (COLE) - V Encontro de Jovens e Adultos Trabalhadores na Universidade Estadual de Campinas, jul. 2001.

JELIN, Elizabeth. Os trabalhos da memória. 2. ed. Lima: IEP, 2012.

MARX, Karl. O capital. São Paulo, Abril Cultural, v.1, p. 81-257, 1980.

MARX, Karl. A ideologia alemã. São Paulo: Hucitec, 1999a.

MOTTA, Rodrigo Patto Sá. As universidades e o regime militar: cultura política brasileira e modernização autoritária. Rio de Janeiro: Zahar, 2014.

OLIVEIRA, Betty Antunes de. Aprendendo a ser educador "técnico + político". Revista Educação e Sociedade. São Paulo, n. 15, p. 20-31, ago. 1983.

OLIVEIRA, Betty Antunes de. A socialização do saber sistematizado e a dimensão política da prática especificamente pedagógica. Em aberto. Brasília, ano 4, n. 26, abr./jun., 1985.

REIS, Renato Hilário dos. A constituição do ser humano: amor-poder-saber na educação/alfabetização de jovens e adultos. Campinas, São Paulo: Autores Associados, 2011.

RICOEUR, Paul. A memória, a história, o esquecimento. Campinas, São Paulo: Ed. Unicamp, 2007.

SOARES, Leôncio. As especificidades na formação do educador de jovens e adultos: um estudo sobre propostas de EJA. Educação em Revista, Belo Horizonte, v. 27, n. 2, p. 303-327, ago. 2011.

Submetido em março de 2020

Aprovado em setembro de 2020

\section{Informações dos autores}

Maria Luiza Ferreira Duques

Doutoranda em Memória: Linguagem e Sociedade pela Universidade Estadual do Sudoeste da Bahia UESB/ Bolsista FAPESB.

E-mail: luizaduques@hotmail.com

ORCID: https://orcid.org/0000-0002-9949-5183

Link Lattes: http://lattes.cnpq.br/8599187489324553

Cláudio Eduardo Félix dos Santos

Doutor em Educação pela Universidade Federal da Bahia - UFBA. Professor adjunto da Universidade Estadual do Sudoeste da Bahia - UESB.

E-mail: cefsantos8@gmail.com

ORCID: https://orcid.org/0000-0003-0545-1102

Link Lattes: http://lattes.cnpq.br/7594684135461900 